\title{
Engaging children in genomics research: decoding the meaning of assent in research
}

\author{
Benjamin S. Wilfond, MD ${ }^{1}$ and Douglas S. Diekema, MD, MPH ${ }^{1}$
}

This article considers how to approach assent from children for genomics research. We examine the "protection" rationale for assent, which emerged in the context of a historical debate regarding whether it was ever acceptable to subject children to risks of research for the benefit of others. We also consider the "development" rationale for assent, which has been articulated for pediatric clinical practice, as an alternative approach for addressing this issue. We consider these rationales in light of the more recent literature on pediatric assent in the research context, and suggest that "engagement" is a more useful construct. This construct emphasizes that children have development capacities that should be respected and includes a limited role for assent to allow children to protect themselves. Engaging children does not require disclosure of all of the benefits and risks of genomics research that might be conveyed to an adult and may permit a degree of parental control over decisions. Using a construct that emphasizes respect can also justify asking children, as they approach adulthood, about their willingness to participate in ongoing genomics research, and yet also permit research to continue if some cannot be reached to obtain consent.

Genet Med 2012:14(4):437-443

Key Words: assent; children; ethics; genomics research; informed consent
Informed consent plays a pivotal role in ensuring that decisions to participate in research are based on an accurate appreciation of benefits and risks and are consistent with participants' values, and that participants' preferences are respected. Applying the principles of informed consent to genomics research has proved to be challenging. ${ }^{1}$ Although the psychosocial and informational risks are easy to identify, the likelihood or seriousness of these psychosocial and informational risks is harder to quantify. Therefore, potential participants may be asked to contemplate an expanding number of issues including (i) whether individual genetic results or incidental findings will be returned; (ii) whether investigators may contact participants to join additional studies; (iii) the challenges of interpreting results that are limited in terms of analytic validity, clinical validity, and clinical utility; (iv) implications of findings for family members; (v) limitations surrounding the ability to maintain confidentiality; (vi) risks of discrimination; (vii) control of data and ability to withdraw data; (viii) acceptability of data sharing; (ix) impact of research findings on communities; and (x) conflicts of interests of researchers related to patentability and profit. There is no consensus about which issues should be covered or what degree of comprehension of this information is necessary, ${ }^{2}$ but informed consent forms for genomics research $^{3}$ may be as complex as those for phase I oncology research that poses life-threatening physical risks. ${ }^{4}$

When genomics research involves children, additional complexities arise. ${ }^{5-7}$ Parental permission replaces informed consent as a primary protection for children, ${ }^{8}$ and the investigator is often expected to obtain the assent of the child. Yet, there is no consensus about how the central pillars of consent-disclosure, comprehension, and voluntariness-should be modified for the assent process. $^{8-11}$ Furthermore, the complexity of genomics research highlights the limitations of current conceptions of child assent, not only for genomics research, but for research in general.

Consider a study that plans to enroll elementary schoolage children who come to a health maintenance organization outpatient facility for a study that includes long-term storage of blood samples and clinical data to be used in future genomics research including whole-exome sequencing. The research plan calls for sharing of the samples and data with other researchers in the future. Is assent necessary to enroll such children? The attempt to answer this pragmatic question points to three deeper questions about the proper role of assent. First, what role should individual capacity play in deciding whether assent should be required? (e.g., how do age, maturity, experience, context, and intelligence matter?) Second, in deciding whether assent should be required, to what degree does it matter whether the inconvenience, discomfort, and harms experienced by a child are directly related to the research as opposed to clinical care? (e.g., does it matter if the blood has already drawn for clinical reasons?) Finally, how should voluntariness and undue influence be understood in the context of assent? (e.g., does it matter if the research team offers the child $\$ 20$ or if the parents offer to take the child for pizza if she agrees?) 
Once it has been decided that assent is an appropriate requirement, other questions arise about the process of obtaining assent from a child. Should there be an "assent form"? Should the assent form say that the child does not have to participate in the study if she does not want to? Should the assent form and discussion address the same issues covered in an informed consent document, such as how blood samples might be used in the future and whether results will be shared with the child's parents? Should a signature be required on the assent form? If there is an assent form, is it necessary that the child understand the form, and how should that comprehension be assessed? How should the research staff respond if the child expresses reluctance to participate in a research-related blood draw?

Further, the developmental trajectory of a child toward adulthood raises additional questions. Should some research not be conducted in young children, or should parental access to research results be restricted, to respect the child's future privacy and control over personal information? If a child turns 18 but cannot be located, is it acceptable to continue to use the samples for research?

To address these questions in this article, we consider the "protection" rationale for assent, which emerged in the context of a historical debate regarding whether it was ever acceptable to subject children to risks of research for the benefit of others. We also consider the "development" rationale for assent that emerged as the justification for assent in pediatric clinical practice, as an alternative construct for addressing this issue. We then examine these rationales in light of the more recent literature on pediatric assent in the research context and suggest that the concept of "engagement" is a more useful construct to guide answers to the questions posed here about assent for genomics research, and research in general.

\section{THE ORIGINS OF ASSENT IN PEDIATRIC RESEARCH}

Whether children should be enrolled in research was controversial during the deliberations of the National Commission in the 1970s. ${ }^{8-11}$ Some commentators expressed the view that because children are not capable of providing informed consent, it was never appropriate to enroll children in research and expose them to risks of harms for the purpose of scientific advancement. ${ }^{12,13}$ The National Commission's deliberations led to two primary protections for children in research ${ }^{14,15}$ that have been codified in current federal regulations. ${ }^{16}$ First, the regulations limit the level of research-related risk of harm to which children can be exposed, regardless of parental or child willingness to accept such risk. The level of acceptable risk varies based upon whether or not the research offers the prospect of direct benefit and whether a child has the disorder or condition under investigation. Although the specific interpretation of what risk/benefit balance is acceptable for children remains contested, the general principle that children should be exposed to less risk than adults is uniformly endorsed. ${ }^{8,17}$ The second protection is the requirement that the assent of the child be sought.
In addition, three other "rules of thumb" that enhance the protection of children in research, although not codified in regulation, are frequently, although not uniformly, adopted. ${ }^{18}$ First, children should only be included in research where the scientific questions cannot be adequately addressed with adult participants. Second, to avoid unexpected harms in children, as much research as possible should be conducted with adult volunteers prior to enrolling children into clinical trials. Finally, when research will enroll children, it is preferable to enroll older children who are capable of assent rather than children who are not capable.

The requirement for assent exists within the context of these other protections. Thus, it should not be expected to duplicate or offer the same protections provided by institutional review board (IRB) assessment of research risks or parental permission to participate in research. The regulations say very little about what qualifies as valid assent. Assent is defined as a "child's affirmative agreement to participate in research. Mere failure to object should not, absent affirmative agreement, be construed as assent."19 Although it is clear that affirmative agreement is critical, it is not clear whether the child needs to agree to some or all elements of the research (e.g., the blood draw, use of tissues or blood collected for clinical purposes, banking of samples, sharing of samples with other researchers, willingness to have parents contacted because of incidental findings) or whether affirmative agreement can include situations in which a child initially objected, but agreed after those initial objections were addressed (e.g., reluctantly holds out an arm after a promise by parents to have additional time to play video games).

The regulations identify three contexts in which assent can be waived by an IRB. First, an IRB can waive the requirement for children who are not capable of assent based on age, maturity, or psychological state. Second, the IRB can waive the requirement for studies that offer the prospect of direct benefit that is not otherwise available outside of research. Finally, the IRB can waive assent for those studies where consent can be waived: i.e., minimal-risk studies where there would be no adverse impact on rights and welfare of participants by waiving consent, and where the research would not be practicable if consent were required. The regulations do not require that assent be documented, leaving the decision about whether and how assent should be documented in the hands of local IRBs.

It is interesting how IRBs generally implement assent. A survey of 188 IRB chairs included a hypothetical scenario involving a 10-cc research blood draw for a clotting study in 8-year-olds. ${ }^{20}$ Respondents indicated that their IRB would require the following disclosures to the children: that the child can refuse (99\%), the purpose of the study (97\%), whether the child will benefit from being in the study (94\%), and serious but rare risks (73\%). Further, $68 \%$ of the IRB chairs would require written information be provided to the child. These findings suggest that many IRBs think of assent of children for participation in research as "quasi-consent" that emphasizes disclosure of the same essential elements of informed consent for adults. But this approach also assumes that the purpose of assent is the same as that of 
informed consent. The underlying rationale behind informed consent is to respect adult preferences and decision making and allow adults to protect themselves from undesired adverse consequences. It is worth asking whether the purpose of assent is a similarly protective one, or whether the requirement for assent serves some other purpose.

In the 1970s, William Bartholome, a leading advocate of a requirement for child assent to research participation, argued that even young children should be treated respectfully and be given age-appropriate information and a role in decision making about research. ${ }^{21}$ Bartholome's focus on pediatric decision making was not restricted to research, and he made similar arguments about the role of children in clinical medical decision making. Understanding how Bartholome's worldview has shaped the involvement of children in clinical decision making offers an alternative framework to the "quasi-consent" model than has been implicitly adopted by many IRBs considering pediatric research.

\section{THE ROLE OF ASSENT IN PEDIATRIC PRACTICE}

Bartholome devoted much of his career to promoting an expanded role for children in clinical decision making, and his influence was reflected by a policy statement issued in 1995 by the American Academy of Pediatrics Committee on Bioethics. ${ }^{22}$ This policy argued for conceptual distinctions between informed consent, a concept relevant to competent adults, and two alternative concepts, parental permission and assent, which are better suited for determining how to engage children, their families, and care providers in clinical decision making. Although the statement focused on clinical practice, the approach can be applied to research as well.

The concept of assent is presented as a way to involve children in decision making about issues that affect them. The rationale for involving children in decision making involves several considerations. First, it represents an important strategy for helping children develop capacities for independent decision making. Second, it provides a mechanism to communicate with a child about his or her care, allowing the child to have a voice in decisions that will affect his or her short- and long-term interests. Finally, and perhaps most importantly, assent is a way of engaging with children that is respectful of them as individuals. By treating a child as someone whose opinions matter, we not only demonstrate respect for the child but also model respectful behavior in the hopes the child will learn to treat others similarly. This conception of assent is more about respect and communication than about protection. In that sense, it serves a different purpose than either informed consent or parental permission.

The spirit behind the notion of assent may not require that in every case a child be told that she does not have to participate in an activity if she does not want to, or that she be given explicit choices at all times. Specifically, the American Academy of Pediatrics policy suggests that children should be informed in a developmentally appropriate manner about their clinical condition, expectations for testing and treatment, and the kinds of experiences they will have. The report goes on to suggest that this engagement should include some assessment of understanding and voluntariness, although it does not clarify what to do when limited understanding or voluntariness is detected. However, the policy makes a final point that sheds some light on this ambiguity: that preferences should be solicited only when they will be followed. This suggests that assent does not require the same level of voluntariness as for adults. What is important is that children should not be given the illusion that their opinion will be a determining factor if adults have already made a final decision.

Consider an 8-year-old child whose pediatrician recommends a complete blood count because of parental concern about fatigue. It might be reasonable to ask the child which arm she prefers to have the blood drawn from, but not whether she does or does not want the blood drawn. It would be important to explain why the test is being done in terms that the child can understand ("We're trying to figure out why you have been so tired lately"). It is also important to explain what she should expect from the blood draw. The child may remain reluctant, and the parent may offer some meaningful rewards to encourage her cooperation. In this example, the spirit that lies behind assent was upheld, even though the child was not aware that the purpose of the test was to look for a very serious illness, even though the child was not given an explicit choice about the having the blood draw, and even though her willingness to agree may have been significantly influenced by an offer of pizza and video games. Although the final decision was ultimately made by those who are responsible for the child's welfare, the child was shown a developmentally appropriate level of respect through efforts to communicate and encourage cooperation.

To appreciate that assent is a much more subtle and complex concept outside of the research context, we can also consider nonclinical decisions that parents make on behalf of their 8 -year-olds. ${ }^{23}$ Parents may make decisions about the child's participation in after-school activities, religious education, visiting grandparents, or helping elderly neighbors with household chores. Different parents may approach these activities with different strategies based on the specific characteristics, values, and preferences of their child, themselves, and their community. In some cases, a parent may ask if the child wishes to visit grandma and even say, "you don't have to do this if you don't want to." In a different context, a parent may tell the child that she is going to visit grandma, even though it will mean that she will miss her soccer game. The child may express disappointment and even argue about why she should not have to go. The parent may offer an explanation or negotiate with the child by offering an incentive. In any case, the spirit behind the concept of assent was not that children should be allowed to make a final decision in every situation, but rather that they be shown some level of respect, even if that extends only so far as allowing them to voice their dissent and have their objections heard.

\section{DECODING "ASSENT" FOR RESEARCH}

The application of assent to research has not evolved as much as it has in the clinical and general childhood contexts. 
Unfortunately, many still think of assent in research as "quasiconsent," rather than an expression of respect. In applying the "quasi-consent" interpretation of assent, most IRBs and investigators may have lost sight of the potential developmental value of assent. The regulatory opportunity to waive "assent" for research that offers a "prospect of direct benefit" contributes to the ambiguity about the potential purpose of assent. Assent, with developmentally tailored engagement as the purpose, may be appropriate both for "beneficial" research and for routine clinical interventions. Further, the typical "assent form" approach to "nonbeneficial" research is not consistent with the discretion that parents are given to make other important life decisions. It may also encourage the view that assent is simply another form of protection that requires not only parents but also children to weigh risks and benefits.

Using this "quasi-consent" construct of assent, Wendler and $\mathrm{Shah}^{24}$ argued that assent should not be required until children are 14 years old, an age at which it might be reasonable to expect them to understand risks and benefits and weigh them appropriately. They distinguish between an autonomy-based rationale for assent and a beneficence-based rationale for dissent. They suggested that assent should not be expected until the age of $\sim 14$ years because children generally have the developmental ability to make adult-like decisions regarding their interests at about that age. However, they argued that a dissent requirement may be important even at a young age to allow children to protect themselves from immediate discomforts or harms. Their paper received substantial commentary that offered a range of views about the age thresholds, the role of dissent, and how to characterize assent (see Table 1), even though there was consensus on several issues. ${ }^{25}$

Diekema ${ }^{26}$ agreed with the dissent issue but suggested that if assent is based on a rationale of respecting children who have interests and preferences, that the age of assent, for at least some research activities, should be school-age children who can both converse and express preferences and interests. Other commentators weighed in, suggesting that part of the disagreement reflected the ambiguity surrounding the concept of assent and that other words should be considered to improve the clarity of the concept.

Table 1 Alternative approaches to conceptualizing engagement with children about research based on age

\begin{tabular}{|c|c|c|c|c|}
\hline Age & $\begin{array}{l}\text { Wendler } \\
\text { and Shah }{ }^{24}\end{array}$ & Diekema $^{26}$ & Botkin ${ }^{27}$ & Joffe 28 \\
\hline $0-4$ & Dissent & Dissent & Distress & \\
\hline $5-10$ & Dissent & Assent & Distress & Involvement \\
\hline $11-13$ & Dissent & Assent & Assent & Agreement \\
\hline 14-17 & Assent & Assent & Consent & Agreement \\
\hline 18 & Consent & Consent & Consent & Consent \\
\hline
\end{tabular}

Botkin ${ }^{27}$ suggests that rather than dissent, we should consider distress, and not permit nonbeneficial research that causes too much distress. Distress is more objectively observable and should be minimized in a research context, particularly one that does not offer any prospect for direct benefit. Botkin also suggests that Wendler and Shah's rationale for the 14-yearold threshold is reasonable, but he would prefer to consider engaging adolescents as a form of "consent" rather than assent. Although parental permission should be necessary as well, the more explicit consent of adolescents is more critical.

Joffe ${ }^{28}$ suggested words other than "assent" were more appropriate. He suggested that we replace "assent" with "agreement" but use a slightly lower threshold than Wendler and Shah, at $\sim 10-11$ years, to connote a more active willingness to participate. For children between 5 and 10 years of age, Joffe would instead use the term "involvement" to both connote the importance of including even younger children in the decisions and to acknowledge a greater role as children get older.

In this article, our goal is not to offer a definitive solution to the ongoing debate that will guide the approach for genomics research ${ }^{5,729-31}$ but to identify some common ground that allows us to answer the pragmatic issues that investigators, parents, and IRBs face. The bedrock of this common ground is an endorsement of the importance of engaging with children in research decisions. Engagement suggests that children matter, but that the final decision will, at least in some cases, be made by the parents. We believe that this engagement approach to assent should be applied to research, as it should also be applied to clinical and other decisions. Research is just one of the many experiences that children may have that may involve benefit to others.

\section{ASSENT FOR GENOMICS RESEARCH}

Even though there remains room for further development and analysis of the concepts of assent, dissent, distress, involvement, and agreement, we believe that sound recommendations can be offered for the questions posed in the introduction to this article. Whether a 10- cc blood draw is for a specific clotting study or enrollment in a health maintenance organization-based biospecimen and data repository, the blood draw itself is likely to be the primary focus of the child, and most plausibly, the source of her immediate reluctance to participate. Further enrollment in a biospecimen and data repository that does not require active participation of a child (e.g., a blood draw) is not likely to be problematic for most children.

We would offer several suggestions for enrolling children in genomics research, regardless of whether this involves a blood draw or a buccal swab or is based on using residual clinical samples that are summarized in Table 2. First, although research staff may be required to obtain the permission of the parents in an effort to keep clinical care and research activities distinct, someone with whom the child has a relationship, including a clinical provider, should obtain assent, whenever possible. When engaging children, 
Table 2 Key questions about the process of engaging children (obtaining assent) for genomic research

\begin{tabular}{ll}
\hline Who should obtain assent? & $\begin{array}{l}\text { Ideally, someone with an established } \\
\text { relationship with the child. }\end{array}$ \\
$\begin{array}{l}\text { What information should be } \\
\text { disclosed? }\end{array}$ & $\begin{array}{l}\text { General information that research } \\
\text { is occurring, that the general goals } \\
\text { of research is to help others, and } \\
\text { the specific involvement of the } \\
\text { child (blood draw or use of existing } \\
\text { samples) to achieve the goal. }\end{array}$ \\
& $\begin{array}{l}\text { Providing some written information } \\
\text { can assist some children in } \\
\text { Is an assent form needed? } \\
\text { signed form may not be necessary or } \\
\text { even useful in all contexts. }\end{array}$ \\
\hline Can incentives be offered? & $\begin{array}{l}\text { Modest incentives, as may be offered } \\
\text { in other contexts, can be appropriate, } \\
\text { as might other modest efforts to } \\
\text { persuade children who are hesitant. }\end{array}$ \\
\hline
\end{tabular}

detailed knowledge of the study is less important than having a comfortable relationship. Second, the child's agreement need not be documented by having the child sign a form. An information sheet written at an age-appropriate level might be provided, but there seems little value added in requiring the child's signature. Third, if an information sheet is provided, it should focus on those aspects of the research that matter to the child and require the child's active participation. The amount of information disclosed to the child does not need be extensive and the otherwise salient issues for genetics that remain controversial for adults certainly need not be explicitly discussed with young children. For example, it is unlikely that most children will understand the concept of "banking" in a meaningful way, and as it does not require the child's active participation, it need not be a part of the assent process. Finally, there is nothing inappropriate about the research team and the parents offering incentives to encourage participation, just as parents offer incentives for many other activities of childhood. ${ }^{32}$ The respect encouraged by an assent process is not undermined by efforts to bargain with the child in an effort to "make it worth the effort" to participate.

These suggestions are not intended to imply that parents, providers, and research staff should be enrolling children and obtaining blood over the child's explicit objections. In fact, great attention should be paid to avoiding distress. When research blood draws are needed, local anesthetics should be used whenever feasible. Parents and providers should remain vigilant to ensure that the blood draw does not cause significant distress and should be prepared to stop in the event that it does. When blood is already being obtained for clinical reasons, obtaining additional blood should be much less problematic. In those cases, the child should not be given a choice about the blood draw, but should be told about it. Most children below the age of 14 will not be able to meaningfully weigh the personal impact of having some extra blood drawn once the needle is in place. We are not suggesting that nothing else be discussed or that assent is not necessary if there is no separate research blood draw. Engaging children briefly about the research remains important if the rationale for assent is to respect children as individuals. A recent survey of adults suggests that most are willing to participate in genomics research but that they wish to know that they are involved in research..$^{33}$ Presumably, this is also what matters to children. For both children and adults, written information that describes the study in general terms can be a way to show respect.

This approach to assent focuses on "engagement" and assumes that the protective aspects of children's participation in genomics research will be provided by parental permission and IRB review. ${ }^{34}$ For example, whether results should be returned to children in a research context, or how to consider the implications for family members will depend on the context, ${ }^{35}$ and we should not expect the assent process to be the primary mechanism to protect children.

\section{ASSENT FOR GENOMICS RESEARCH AS CHILDREN GROW UP}

The paradigm example of an 8-year-old was chosen intentionally to represent an age at which children will be able to understand something about research and express their interests but will not have complex views about genetics research, including the issues surrounding privacy of information, incidental findings, return of results, etc. However, when older children are enrolled in genomics research, a tailored approach to disclosing more information and to increase the emphasis on voluntary participation would be appropriate as their capacities and interests in self-determination increase. Considering the case of middle school-aged children, perhaps the greatest concern for such children might be how sensitive information related to drug use, sexual activity, or pregnancy will be handled. Older children and adolescents should be informed when this kind of sensitive information will be obtained, with whom it will be shared, and be given the choice as to whether they wish to participate. Some genetic information, including recessive carrier status may have similar meaning for adolescents. A recent study of parental focus groups suggests that parents would expect access to such information. ${ }^{31}$ Wilfond and Carpenter ${ }^{36}$ have suggested that control of sensitive information should be clarified and communicated explicitly with adolescents and parents, and suggest that the default should be to respect adolescent privacy of sensitive information. Adolescents should be given the option of not participating when privacy cannot be guaranteed.

An additional issue arises when children transition to adulthood. Some have argued that explicit consent should be obtained from adolescents once they have reached an age of $13-15 .{ }^{27}$ We agree with this approach inasmuch as we agree that adolescents should be given as much information and that their refusals be respected as they would be for adults. Even in this context, parental permission should still be necessary. Although this approach can be applied relatively simply when studies enroll adolescents or when ongoing contact 
with children who were enrolled at younger ages occurs, it can be more complicated for studies that enrolled younger children who then become adolescents or adults but with whom the researchers have lost contact. Some have suggested that research using specimens from these individuals can continue without the consent of the individual as long as the samples or individual sequence data are not shared beyond the original research team..$^{5,30}$ A recent survey of 1,186 adults included a hypothetical scenario in which samples had been collected from infants and asked respondents whether it would considered acceptable for ongoing research to occur if these individuals who were now adults were not available to give consent. ${ }^{37}$ Twenty-six percent indicated that they would consider it unacceptable for researchers to continue to use their samples. Although the inferences of this hypothetical survey are limited, such data point out that some adults do in fact object to the continued use of data and samples that were obtained from them as children. This reinforces the value of continued engagement with children involved in genomic research to permit those with strong views to have the opportunity to disengage. Yet in those contexts where such engagement does not occur successfully, a default approach of continued use is consistent with the parental decision for their child to contribute to scientific knowledge.

\section{CONCLUSION}

Although standard regulatory approaches treat children as "mini-adults," this is not explicitly required or ethically justified. The complexity of information about genetic research should be communicated to parents, whose role is to protect the child. The requirement of assent should focus on issues of concern to the child and emphasize communication and reduction of distress. What is most important is that children be engaged in a developmentally appropriate manner. Assent discussions do not necessarily require disclosure of all benefits and risks, particularly those that are rare. How much information should be disclosed will vary with the age and maturity of the child. For children aged 10 and under, the primary focus should be on decisions about blood draws and other sources of immediate distress. Providing written information, or using other approaches, to communicate that a researcher will have ongoing access to samples and data may become important for children as they get older. For children aged 11-13, a greater emphasis on privacy from parents may be important, although this may be less of an issue for much genetic research, in contrast to more understandably sensitive topics. By the age of 14, researchers should engage as they might with adults, even though additional parental permission will be obtained in most contexts.

\section{ACKNOWLEDGMENTS}

Preparation of this article for this symposium and presentation at the conference associated with the symposium was supported in part by National Institutes of Health, National Human Genome Research Institute (NHGRI) grant no. 2-R01-HG003178 on "Managing Incidental Findings and Research Results in Genomic
Biobanks \& Archives" (S. Wolf, principal investigator). B.S.W. was also supported by P50-HG-3374 (NHGRI) and UL1 RR025014 (National Center for Research Resources).

\section{DISCLOSURE}

The authors declare no conflict of interest.

\section{REFERENCES}

1. McGuire AL, Beskow LM. Informed consent in genomics and genetic research. Annu Rev Genomics Hum Genet 2010;11:361-381.

2. Wendler $D$. One-time general consent for research on biological samples. BMJ 2006;332:544-547.

3. Hull SC, Gooding H, Klein AP, Warshauer-Baker E, Metosky S, Wilfond BS Genetic research involving human biological materials: a need to tailor current consent forms. IRB 2004;26:1-7.

4. Horng S, Emanuel EJ, Wilfond B, Rackoff J, Martz K, Grady C. Descriptions of benefits and risks in consent forms for phase 1 oncology trials. N Engl J Med 2002;347:2134-2140.

5. Hens K, Cassiman JJ, Nys H, Dierickx K. Children, biobanks and the scope of parental consent. Eur J Hum Genet 2011;19:735-739.

6. Burke W, Diekema DS. Ethical issues arising from the participation of children in genetic research. J Pediatr 2006;149(suppl 1):S34-S38.

7. Ries NM, LeGrandeur J, Caulfield T. Handling ethical, legal and social issues in birth cohort studies involving genetic research: responses from studies in six countries. BMC Med Ethics 2010;11:4.

8. Diekema DS. Conducting ethical research in pediatrics: a brief historical overview and review of pediatric regulations. J Pediatr 2006;149(suppl 1): S3-11.

9. Unguru Y, Coppes MJ, Kamani N. Rethinking pediatric assent: from requirement to ideal. Pediatr Clin North Am 2008;55:211-22, xii.

10. Ungar D, Joffe $S$, Kodish E. Children are not small adults: documentation of assent for research involving children. J Pediatr 2006;149(suppl 1): S31-S33.

11. Wendler DS. Assent in paediatric research: theoretical and practical considerations. J Med Ethics 2006;32:229-234.

12. Ross LF. Informed consent in pediatric research. Camb Q Healthc Ethics 2004; 13:346-358.

13. Jonsen AR. Nontherapeutic research with children: the Ramsey versus McCormick debate. J Pediatr 2006;149(suppl 1):S12-S14.

14. Freedman B, Fuks A, Weijer C. In loco parentis. Minimal risk as an ethical threshold for research upon children. Hastings Cent Rep 1993;23:13-19.

15. Bartholome WG. In defense of a child's right to assent. Hastings Cent Rep 1982;12:44-45.

16. 45 C.F.R. $§ 46$. Protection of Human Subjects: Subpart D-Additional Protections for Children Involved as Subjects in Research, 1991.

17. Ross LF. Children in medical research: balancing protection and access-has the pendulum swung too far? Perspect Biol Med 2004;47:519-536.

18. Wendler $D$. Three steps to protecting pediatric research participants from excessive risks. PLoS Clin Trials 2006;1:e25.

19. 45 CFR §46. Protection of Human Subjects, 1991.

20. Shah S, Whittle A, Wilfond B, Gensler G, Wendler D. How do institutional review boards apply the federal risk and benefit standards for pediatric research? JAMA 2004;291:476-482.

21. Bartholome WG. A new understanding of consent in pediatric practice: consent, parental permission, and child assent. Pediatr Ann 1989;18:262-265.

22. American Academy of Pediatrics Committee on Bioethics. Informed consent, parental permission, and assent in pediatric practice. Pediatrics 1995:95:314-317.

23. Ross LF. Children, Families, and Health Care Decision Making. Clarendon: Oxford, New York, 1998.

24. Wendler $D$, Shah $S$. Should children decide whether they are enrolled in nonbeneficial research? Am J Bioeth 2003;3:1-7.

25. Wendler D, Shah S. A response to commentators on "Should children decide whether they are enrolled in nonbeneficial research?". Am J Bioeth 2003;3:W37-W38.

26. Diekema DS. Taking children seriously: what's so important about assent? Am J Bioeth 2003;3:25-26.

27. Botkin JR. Preventing exploitation in pediatric research. Am J Bioeth 2003;3:31-32 
28. Joffe $\mathrm{S}$. Rethink "affirmative agreement," but abandon "assent". Am J Bioeth 2003;3:9-11.

29. Hens K, Nys H, Cassiman JJ, Dierickx K. Risks, benefits, solidarity: a framework for the participation of children in genetic biobank research. J Pediatr 2011;158:842-848.

30. Gurwitz D, Fortier I, Lunshof JE, Knoppers BM. Research ethics. Children and population biobanks. Science 2009;325:818-819.

31. Kaufman D, Geller G, Leroy L, Murphy J, Scott J, Hudson K. Ethical implications of including children in a large biobank for genetic-epidemiologic research: a qualitative study of public opinion. Am J Med Genet C Semin Med Genet 2008;148C:31-39.

32. Wendler D, Rackoff JE, Emanuel EJ, Grady C. The ethics of paying for children's participation in research. J Pediatr 2002;141:166-171.
33. Hull SC, Sharp RR, Botkin JR, et al. Patients' views on identifiability of samples and informed consent for genetic research. Am J Bioeth 2008;8:62-70.

34. Tarini BA, Tercyak KP, Wilfond BS. Commentary: Children and predictive genomic testing: disease prevention, research protection, and our future. J Pediatr Psychol 2011;36:1113-1121.

35. Denny CC, Wilfond BS, Peters JA, Giri N, Alter BP. All in the family: disclosure of "unwanted" information to an adolescent to benefit a relative. Am J Med Genet A 2008;146A:2719-2724.

36. Wilfond BS, Carpenter KJ. Incidental findings in pediatric research. J Law Med Ethics 2008;36:332-340, 213.

37. Goldenberg AJ, Hull SC, Botkin JR, Wilfond BS. Pediatric biobanks: approaching informed consent for continuing research after children grow up. J Pediatr 2009;155:578-583. 